\title{
The impact of industrial revolution 4.0 on international trade
}

\author{
Jan Rymarczyk
}

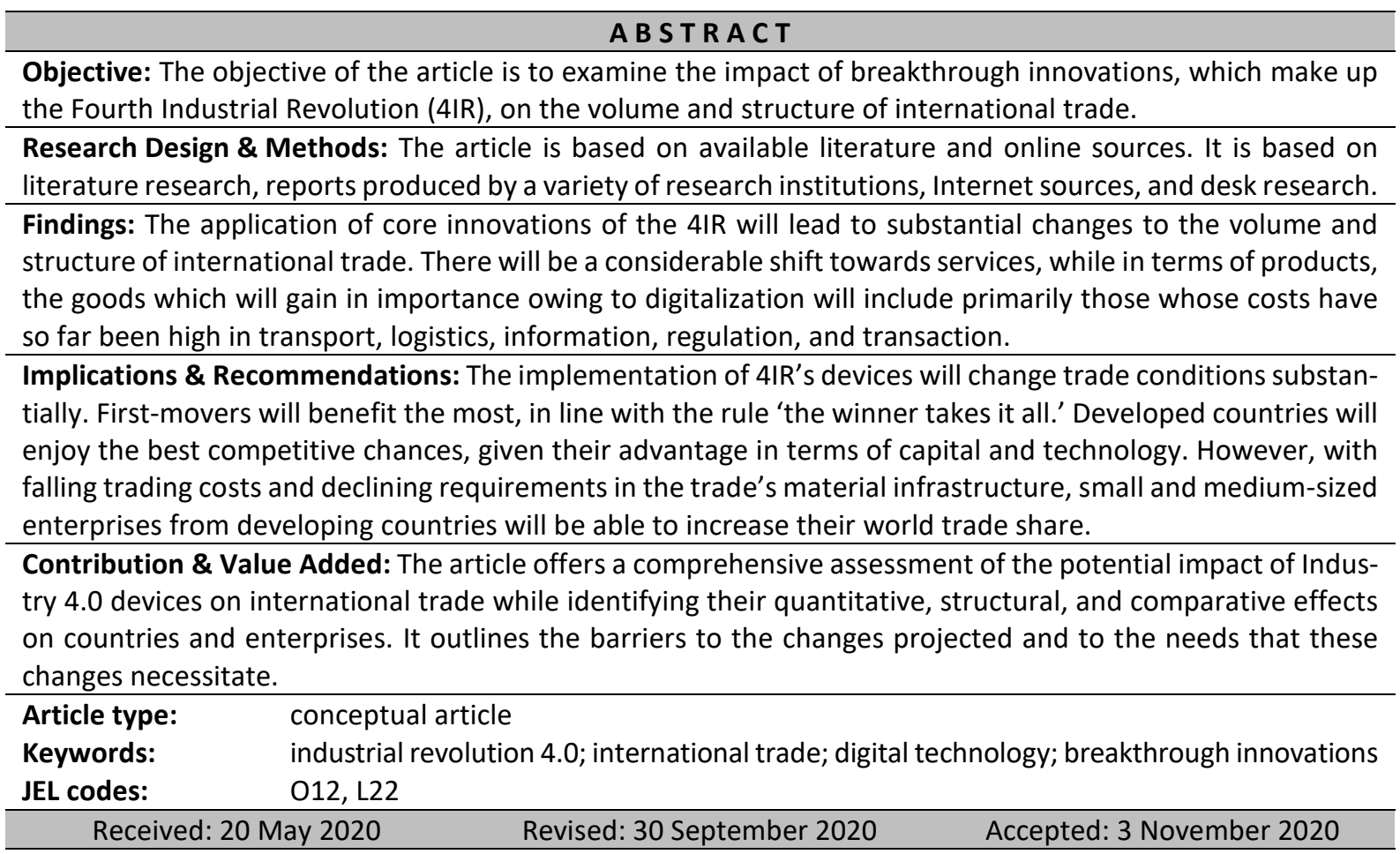

\section{Suggested citation:}

Rymarczyk, J. (2021). The impact of industrial revolution 4.0 on international trade. Entrepreneurial Business and Economics Review, 9(1), 105-117. https://doi.org/10.15678/EBER.2021.090107

\section{INTRODUCTION}

Over the centuries, the most important generator of changes observed across economies of different countries has been technical progress (Rymarczyk, 2020; Upadhyay, 2019; Hradecka, 2019). It determines not only countries' internal processes of development but also their internationalization, which effects in the globalization of the world economy, especially in the context of catching-up economies (Paliokaite, 2019). Modern technologies and breakthrough inventions or innovations have altered the nature of production and trade enormously, both domestically and internationally (Młody, 2018; Świadek, Dzikowski, Tomaszewski, \& Gorączkowska, 2019; Świadek \& Gorączkowska, 2020; Gorączkowska, 2020). Thus, it shapes strategic options for managers in all sectors of national economies (Majerova, 2019; Pini, 2019), in particular promoting e-commerce and e-business (Leko Šimić, Biloš, \& Mijoč, 2019). Their currently unfolding implementation - which involves the convergence of physical, digital, and biological spheres - is referred to as the Fourth Industrial Revolution (4IR). Its core instruments comprise the Internet of Things (IoT), artificial intelligence (AI), cyber-physical devices, 3D printing, blockchain, big data, cloud computing, nanomaterials, and synthetic biology (Sieja \& Wach, 2019). 
Some of them have already been put into practice, others remain in statu nascendi, while still others are being projected.

The changes that are projected to occur in international trade as a result of these technologies and innovations will entail the following: (i) a shift in the nature of trade, (ii) an increase in its volume, (iii) changes to its structure and to (iv) the impact of the comparative advantage factors of trade partners. Trade will become largely digital. We will see a considerable decline in trade costs, increased trade transparency and security together with a guarantee that contracts are performed reliably and goods and services are paid for. With falling costs and reduced information asymmetries, in particular small and medium-sized enterprises, virtual companies and entities from developing countries are likely to see their trade share grow.

In terms of the sectoral structure of international trade, it is predicted that the share of services will increase, while in terms of products, we will see a growing share of goods whose costs have so far been high in terms of transport, logistics, certifications, contracting and border crossing, along with an increase in digital goods or those with a high content of this component. Will such changes indeed take place in international trade? The logic of production and trade development influenced by technical progress suggests that these changes are very likely. However, they may unfold differently, owing to events that are now impossible to predict.

The current article offers a comprehensive assessment of the potential impact of Industry 4.0 devices on international trade while identifying their quantitative, structural and comparative effects on countries and enterprises (Androniceanu, Georgescu, Tvaronavičiene, \& Androniceanu, 2020, p. 5). Moreover, the article outlines the barriers to the changes projected and needs these changes necessitate, including the implementation of measures aimed at removing these barriers. It is very likely that the international trade situation is going to develop as presented in the article, considering, among other things, that these changes have already begun, albeit in a fragmented manner. Still, we cannot rule out that unexpected events would not slow down globalization - along with international trade as its key instrument - such as the current coronavirus pandemic (Ratten, 2020) or a protective trade policy like the trade wars waged by the US President Donald Trump (Nwoke, 2020; Park, 2017).

The objective of the current article is to examine the impact of breakthrough innovations, which make up the 4th Industrial Revolution, on the volume and structure of international trade. In particular, I will attempt to determine what effect these innovations will have on international trade costs and how will they change the relevance of factors of comparative advantage for this trade.

The first section discusses the impact of new technologies on international trade costs, which are the most critical determinant of the volume and structure of trade. The next section addresses the changes likely to occur in the trade volume and its structure in terms of its sectors and products. The two following sections focus on the servitisation of international trade, and how the relative importance of the countries' comparative advantages changes for the trade, while the latter section is concerned with the barriers faced by trade digitalization.

\section{RESEARCH METHODOLOGY}

The current article is based on available literature and online sources. This is a theory development article, which relies on literature review and desk research (Rymarczyk, 2020).

This conceptual article derives research propositions from literature review and desk research of current business press papers, professional reports, company web pages, and blogs because this subject is relatively new in the theory of economics and international business. I searched through secondary literature with the combination of two screening terms: 'industrial revolution' or 'industry 4.0' and 'international trade.' Let me emphasise that many of these sources present similar perspectives, but the current article cites only the most relevant ones for further analysis.

To conclude, this article should be considered as a conceptual paper, in which literature review and desk research lead to the development of theoretical propositions. As for the scientific approach, this article uses a qualitative design of research, the method of indirect observation, cause-effect analysis, and predictive synthesis, modelling, induction, and description. 


\section{LITERATURE REVIEW AND THEORY DEVELOPMENT}

The basics and theoretical considerations about the Fourth Industrial Revolution (4IR, Industry 4.0) have been widely discussed in the literature (Maciejewski \& Głodowska, 2020; Rymarczyk, 2020; Ślusarczyk, 2018; Liu, 2017; Krykavskyy, Pokhylchenko, \& Hayvanovych, 2019; Pisar \& Bilkova, 2019). It seems that it is now high time to undertake a more in-depth analysis according to selected themes. As mentioned above, the overall literature review and theory development is divided into five analytical thematic areas. The first analytical section will discuss the impact of new technologies on international trade costs, which are the most critical determinant of the volume and structure of trade. The second analytical section will address the changes likely to occur in the trade volume and its structure in terms of its sectors and products. The third analytical section will focus on the servitisation of international trade, while the fourth will show how the relative importance of countries' comparative advantages changes for the trade. The fifth analytical section will concern the barriers faced by trade digitalization.

\section{The Impact of Breakthrough Technologies on International Trade}

Digital technologies make the costs of the cross-border trade decrease (Ismail, 2020). These costs are made up of information, transport, logistics, border-crossing, transaction costs, and costs linked to trade policies. A smooth and inexpensive flow of reliable information will facilitate the search for products, services and their most optimal manufacturers. Furthermore, it will be easier to establish contact with manufacturers, to verify their reliability and quality of their products, to conduct trade negotiations and sign contracts, to transport, store, and tranship goods, to provide cross-border clearance and make payments.

The key issue is to acquire information on markets and potential partners for exporting or importing goods, on current custom provisions, standards required in a given country, and consumer preferences. Online platforms play an enormous role in providing this information and in establishing contacts between exporters and importers, manufacturers, and consumers. The platforms help to overcome the barrier of information asymmetries as regards the quality of goods and reliability of their providers, thus increasing trust and confidence between partners. A great number of platforms act as intermediaries between buyers and sellers, ensuring that delivered products will be exactly as described, in addition managing buyers' claims and protecting them against rogue sellers (Tan, 2017, p. 8; Linz et al., 2017, pp. 12-26; WTO, 2018, pp. 72-77; Manyika et al., 2016, pp. 31-36). Online ratings of buyers' and sellers' recommendations - including their interactions through feedback - contribute to the greater confidence and growing number of users of these platforms. These features in consumers behaviour allow to achieve essential competitive advantages despite of distance in global environment ( $\mathrm{Hu}$, Ocloo, Akaba, \& Worwui-Brown, 2019; Nwabueze \& Mileski, 2018). With the communication cost declining, numerous small and medium-sized enterprises will play a bigger part in international trade, and so will individual entities from developing countries. Their share in trade will grow along with the number and popularity of online platforms. Price transparency and product information will toughen competition between sellers to the benefit of consumers. Global online platforms, such as Google, Amazon, Facebook, Apple (the so-called GAFA), Alibaba, eBay, Flipkart, and Route connect sellers and buyers worldwide (Weber \& Gneuss, 2017, pp. 6-7). For instance, Facebook's active user base boasts as many users as China's population, i.e. about 1.4 billion (Manyika et al., 2016, p. 33). With transaction costs reduced, their greater transparency and easiness with which one can obtain information, the online platforms are becoming the largest and most effective markets for the global trade. Major transnational corporations create their own e-commerce and innovation platforms, which make up the components of the international business environment (Grochal-Brejdak \& Szymura-Tyc, 2018).

International flows of goods and services are mostly conducted under intra-corporate supply chains. In this respect, the operations between the parent entity of transnational corporations and their branches require perfect coordination and monitoring. For these corporations to be managed effectively, it is crucial to have information flowing between them and terminal operators, shippers, 
carriers, custom brokers, insurers, and many other entities involved in these processes. Without modern information and communication technology (ICT) devices (Lechman, 2018; Lula et al., 2019; Kavcakova \& Kocisova, 2020) - especially the Internet of Things, big data, and cloud computing - their smooth operations and development would not be possible, while the interconnection costs would be several times higher (Gravili et al., 2018; Dima \& Maassen, 2018).

What continues to be a major barrier for international trade is transport and logistics costs. Despite having applied such innovations as containerization, multi-modal transport, logistics centres, GPS, and modern means of transportation, these costs still account for the largest share of overall trading costs. What should bring a substantial cost reduction in this area is the implementation of the following innovations: robotisation, artificial intelligence, the Internet of Things, and 3D printing. Combining intelligent robots with the Internet of Things will enable firms to optimize routes for cargo flows, further allowing for tracking, adjustment, and selection of sites for warehousing and transhipment. The latter two operations, along with packaging and co-packing, can be fully automated. However, a true game changer in transport will be self-driving cars. Not only will they be cheaper, but they will also be safer, faster, and more punctual. This will be of major relevance for transporting time-sensitive goods (e.g. consumer goods) or for supply chains, particularly those based on a just-in-time system.

Furthermore, the future costs of transport and logistics might prove to be overall significantly lower thanks to 3D printing technology, which allows firms to locate final production lines in close proximity of consumers. Products could be manufactured in one place, partly based on successive production stages controlled by algorithms. This should reduce the number of subcomponents and components that require transfer within supply chains, hence reducing the volume and frequency of cargo to be transported. Choosing a production location in developing countries because of their low labour costs will no longer be a factor determining the geography of value chains (Wyciślak, 2017; Pohlova, Smutka, Laputková, \& Svatoš, 2018). This will be further reinforced by automation, robotisation, computerisation, and the application of artificial intelligence in manufacturing. Transnational corporations (TNC) are currently relocating a bulk of their fragmented production from developing countries back to their homelands. Furthermore, manufacturing goods in places where they are to be sold will meanwhile allow firms to avoid customs and other barriers and border crossing costs (Strange \& Zucchella, 2017, p. 178; Leering, 2017, pp. 20-22; OECD, 2017, pp. 20-21). The time needed for production and delivery of products to consumers will also be reduced, with the option of having the products tailored to individual consumer needs.

Electronic systems using the Internet of Things (IOT) and Blockchain can contribute to the reduction of costs that arise from having to document transactions compliance with applicable custom provisions and custom procedures, but also sanitary, veterinary, and phytopathological standards, environmental protection regulations, quality standards, and regulations regarding product licensing, origin, and authenticity. Moreover, automated online translation systems will remove language barriers. These regulations and standards vary across nations and are subject to changes depending on the objectives of current trade policies. By providing effective and automated data management, i.e. their adequate collection, selection, and processing, firms will be able to avoid redundant procedures, conflicts of laws, and claims, while making it easier to detect fraud and abuse; as a consequence, there will emerge a faster, more transparent, and safer transfer of goods across borders. Smart contracts will allow automatic payments and the customs, verification, and certification of procedures. E-commerce platforms and mobile banking have already been facilitating cross-border payments (Ganne, 2018, pp. 30-55). The payment systems installed on online platforms such as American Amazon Pay, PayPal, and Chinese Alipay allow firms to avoid the infrastructure of correspondent banks, thus saving time and costs. However, the future belongs to Blockchain (Nowiński \& Kozma, 2017). Smart contracts will ensure automated payments, eliminating bank intermediation costs and currency exchange costs. A controversial issue is whether payments will be made in cryptocurrencies; if so, this would further contribute to lowering financial transaction costs. This will depend on a number of factors, including monetary policies pursued by different countries, whether cryptocurrencies will be adopted as a means of payment, and whether their value will stabilize; cryptocurrencies have so far shown extreme volatility (Brown \& Whittle, 2020).

The significant reduction of costs involved in obtaining information, searching for and contacting trade partners, concluding and recording transactions, and - crucially - the costs of goods delivery should 
all have a major impact on the volume of global trading. It is not only current exporters and importers that will be able to increase their share in cross-border flows; new exporters and importers are likely to emerge for whom the costs used to represent a barrier, a threshold marking their ability to enter international trade. These will predominantly be - as already stated above - small and medium-sized enterprises, entities of different sizes, from developing countries, emerging markets, and individuals.

\section{Changes in the Volume and Structure of International Trade}

The broad application of digital technologies resulting in cost reduction engender an increase in the volume of trade while altering its structure (Ismail, 2020). Trade in some goods will increase, decline in others, while still other goods will gradually disappear, a process that is partly already happening. We will see an increase in trade in goods whose costs are higher in terms of transport, logistics, information, regulations, and transaction (WTO, 2018, pp. 88-92). Trading in time-sensitive goods that is, intermediate goods transferred within supply chains - will therefore expand and so will perishable consumer goods. Greater transparency of trade and easier identification of products will reduce costs driven by the need of certification, which should contribute to certification-intensive goods having a bigger share in trade.

The same effect should be noticeable for goods with information- and transaction-intensive costs. Reduced information asymmetry through online platforms, elimination of transaction intermediaries, automated transactions and payments conducted with Blockchain technology can secure a larger trade share of contract-intensive goods.

Trading in information technology goods will show an upward trend. What will grow is the trade of information carrier hardware, smartphones, tablets, mobile phones, and other devices with large knowledge content, along with those involved in the installation of modern technologies like sensors, cameras, or liquid crystal displays (Lula et al., 2019).

Traditional goods to which a digital component will be added (digital wrapper) can have a promising future. Classic examples here are driverless cars which are already at a testing stage, robots equipped with artificial intelligence, smart houses, clothes, shoes, and the radio-frequency identification technology (RFI), which enables transport routes to be tracked, monitored, identified, and adjusted. Digital components are also applied in equipment designed to increase warehousing efficiency (Lund \& Manyika, 2016, pp. 4-5; Melzer, 2016, p. 37).

A series of modern technologies such as the loT, cloud computing, big data, 3D printing, and online platforms will shape the volume and share of customized products in the global trade structure. The greater supply of more diversified goods should correspond to the greater demand for goods satisfying consumers' individual preferences (WTO, 2018, pp. 91-92). This process is explained by theories of demand and supply in international trade, i.e. the similarity of preferences theory, the product diversification theory, and the intra-branch trade theory (Rymarczyk, 2012, pp. 117-120). Collecting and computing big data in the 'cloud' allow for infinite amounts of elements that shape consumer taste to be classified and used in mass customization. On the other hand, flexible production systems using reprogrammable robots allow for the manufacturing of small batches or even individual items. What will prove to be of major importance for mass customization is 3D printing - i.e. the manufacturing of personalized products in the vicinity of consumers - which relies on algorithms obtained through the Internet. This production will ensure the high quality of products, close fit to consumer needs, and low transportation and production costs. This means that the majority of costs involved in international trade will be eliminated, which will certainly positively affect its volume. This will also entail a change in trade structure, because we will witness the partial elimination of the transport of intermediate goods, alongside value chains and finished products. On the other hand, the flows of raw materials and components are likely to increase, not unlike the equipment needed for the production based on the 3D system, should this equipment be unavailable on site.

Meanwhile, an opposite trend will become evident for a series of digitalizable goods. Trade in such goods as books, brochures, music stored on CDs, DVDs, and video cassettes, maps, postcards, journals, newspapers, and videogames will decline. The physical form of these goods is increasingly replaced by download services such as e-books, e-films, e-journals, and online games. 
What could also impact the cross-border transfer of finished products is the sharing economy (WTO, 2018, pp. 95-97; Lopez-Gonzalez, 2017, pp. 15-16). With transportation services becoming ever more user-friendly and inexpensive, households are likely to feel dissuaded from buying new cars. On the other hand, what could create new streams for demand are models of hybrid vehicles that are environmentally friendly, equipped with software and hardware as well as driverless cars.

One could also expect the share of small shipments of minor value to grow within the structure of international trade. High trade costs rendered their cross-border transfer uneconomical. By reducing these costs significantly, digital technologies will remove the major barrier that small and mediumsized enterprises face when trading in relatively small quantities of goods, including born global companies and those from developing countries and emerging markets. The emergence of new players will drive the expansion of the international trade volume while considerably reshaping its structure.

\section{The Servitisation of International Trade}

Digital technologies will reduce the costs of cross-border transfer of not only goods but also services to the extent that they will even determine the provision of services in that they will remove the need for spatial proximity between providers and consumers (Ismail, 2020). In parallel with the steady growth of their volume and share in the creation of a global product, their importance and share in international trade will rise considerably, too. The servitisation of economic flows across borders will emerge in the wake of the development of the digital structure, thus enabling their electronic online delivery. Numerous services are already provided through Voice over Internet Protocol, e-mails, and online platforms, which allow companies from different countries to use their comparative advantage (WTO, 2018, pp. 80-86). Through communication networks, services can be provided regardless of distance, including sale, marketing, legal, financial, insurance, IT (information technology / information and communication technology), computer, technical, and other services involved in assisting transactions of international trade, as mentioned above. In this area, their share has been growing more rapidly than that of traditional services such as transport and travelling, which also employ digital services. The application of telerobotics will allow medical services (surgery, mental therapy) to be conducted from a distance; unlike today, when they require face-to-face contact. This contact could be replaced by telepresence, or a virtual presence in a space other than where the physical person is actually located. This type of digital services is already happening in a variety of activities such as business, science, and culture. Using this technology, managers from the parent entity of transnational corporations can supervise their foreign branches or monitor what happens in their offices while they are away. Digital technology supports the development of e-learning and the remote provision of knowledge in the form of courses for tens of millions of people globally (Ratten, 2020).

Moreover, major importance, and one that is on the rise, is being gained by non-standard broker services enabled by online platforms and delivered to individual clients. These services cover such areas as accounting, auditing, advisory, management, programming, designing, testing, analysing, and marketing. They can be conducted largely autonomously, by using artificial intelligence, the Internet of Things, and other revolutionary devices. Managing assets, liquidity, and fixed assets with modern technologies (wealth tech management) is becoming an alternative that grows rapidly in relation to traditional services for wealth management (Axxsys, 2018, pp. 5-7). Robo-advisers are enjoying a growing popularity in technical, legal, and financial services, including pension and insurance funds, venture capital, private equity, and hedge funds.

It is estimated that $50-70 \%$ of stock-exchange trading in the USA and $20-40 \%$ in Europe bases on algorithms, which means that orders are transacted via electronic platforms in the form of specific computer automated algorithms that contain relevant instructions and speedily respond to changing security prices and other transaction conditions. This is referred to as high-frequency trading conducted between intelligent robots (Woodward, 2017, p. 11).

Online platforms using digital technologies play a part in the development of peer-to-peer services; in other words, they provide access to services via mobile applications, thus allowing for direct contact to be established between providers and recipients of service. They reduce the costs involved in having to search for partners, their communication, and they assure that the service will be performed. This 
is the above-mentioned sharing economy, which is quickly becoming more ubiquitous, primarily in transportation services (Uber) and accommodation (AirBnB).

\section{Shifts in the Relative Importance of Comparative Advantage Factors for Trade}

Classical, neoclassical, and modern theories of international trade offer a detailed analysis of what gives rise to its development, emphasizing the importance of differences between individual countries in terms of how they are equipped with material and nonmaterial factors. Traditional factors that determine whether a particular country has comparative advantage include labour, capital, and land: raw materials, climate, natural environment, and arable land. The 4IR's groundbreaking technologies will dramatically reshape the relative importance of these factors. A critical role will be played by capital resources, both physical and human, i.e. knowledge and its application. The research and development (R\&D) costs involved in designing, manufacturing, testing, and implementing innovations are huge. Although the importance of start-ups is paramount to innovation, the complex process needed for an innovative idea to be realized and then commercialized remains largely in the hands of transnational corporations whose capital affords them comparative advantage. This is evident in the fact that the 4IR was actually launched by transnational corporations (TNCS) in Germany and is being further advanced by major corporations in other world economic powers. However, this suggests that the technological gap between developed and developing countries might widen.

Represented by digitalization, automation, and robotisation, the advanced technology applied in production and services will diminish the relevance of comparative advantage represented by cheap labour, whose large resources are available in developing countries. According to a UNCTAD and World Bank report, two-thirds of workers in developing countries will lose their jobs over the next two decades due to digitalization, automation, and reshoring (Kozul-Wright, 2016, p. 1). On the other hand, the importance of the comparative advantage of highly skilled workers will grow, especially with respect to workers whose skills are complementary with the new technologies (Aepli et al., 2017, pp. 3437). The appropriate demand for highly qualified workers able to serve new technological processes has been a problem in hiring and retaining skilled employees in recent years, especially in developing countries (Bilan, Mishchuk, Roshchyk, \& Joshi, 2020).

The countries' comparative advantage generated by well-developed physical infrastructure of trade - like ports, railways, terminals, custom clearance facilities - will lose the importance it has today, owing to the digitalization of cross-border flows, with the exception of telecommunication and energy infrastructure. The latter will be essential in the development of digitally intensive sectors of economy and commerce. Communication networks, computers, data centres, and in particular the production of bitcoins requires massive amount of energy.

The extremely important factor of comparative advantage - which is a large market size - will only grow in significance in the era of digitalization. In digitally-intensive sectors, the economics of scale and scope are primarily associated with access to a possibly large information base, ensured largely by having a big domestic market, as compared to markets in smaller countries (Agrawal, 2019, pp. 468-471).

Trade digitalization is expected to raise the comparative importance of countries with strong institutions and good regulations. Yet other factors that contribute to winning advantage in trading are correct, clearly worded, and legally stable regulations, together with adequate regulations in such areas as taxes, environmental protection, contracts for financial flows, intellectual property protection, personal data protection, web content privacy, and strong institutions capable of effective and prompt enforcement of law. Coupled with government policies aimed at supporting the Fourth Industrial Revolution, these elements are part of a set of factors that are the driver of comparative advantage in international trade enjoyed by developed countries when viewed against developing countries (Androniceanu, Kinnunen, \& Georgescu, 2020, p. 12).

Moreover, in mid-term perspective, demand for oil and gas will be to the benefit of those developing countries and emerging markets that have abundant mineral reserves, in particular oil and gas. In long-term perspective, renewable energy is likely to become widespread, along with new methods of its generation. Meanwhile, demand for other mineral resources is likely to decline as new technologies will make a closed-circuit production and recycling of potential waste largely feasibility. 


\section{Barriers to Digital International Trade}

The implementation of the 4IR devices in international trade encounters multiple barriers that will certainly fail to impede the revolution's progress, as has been demonstrated by previous industrial revolutions.

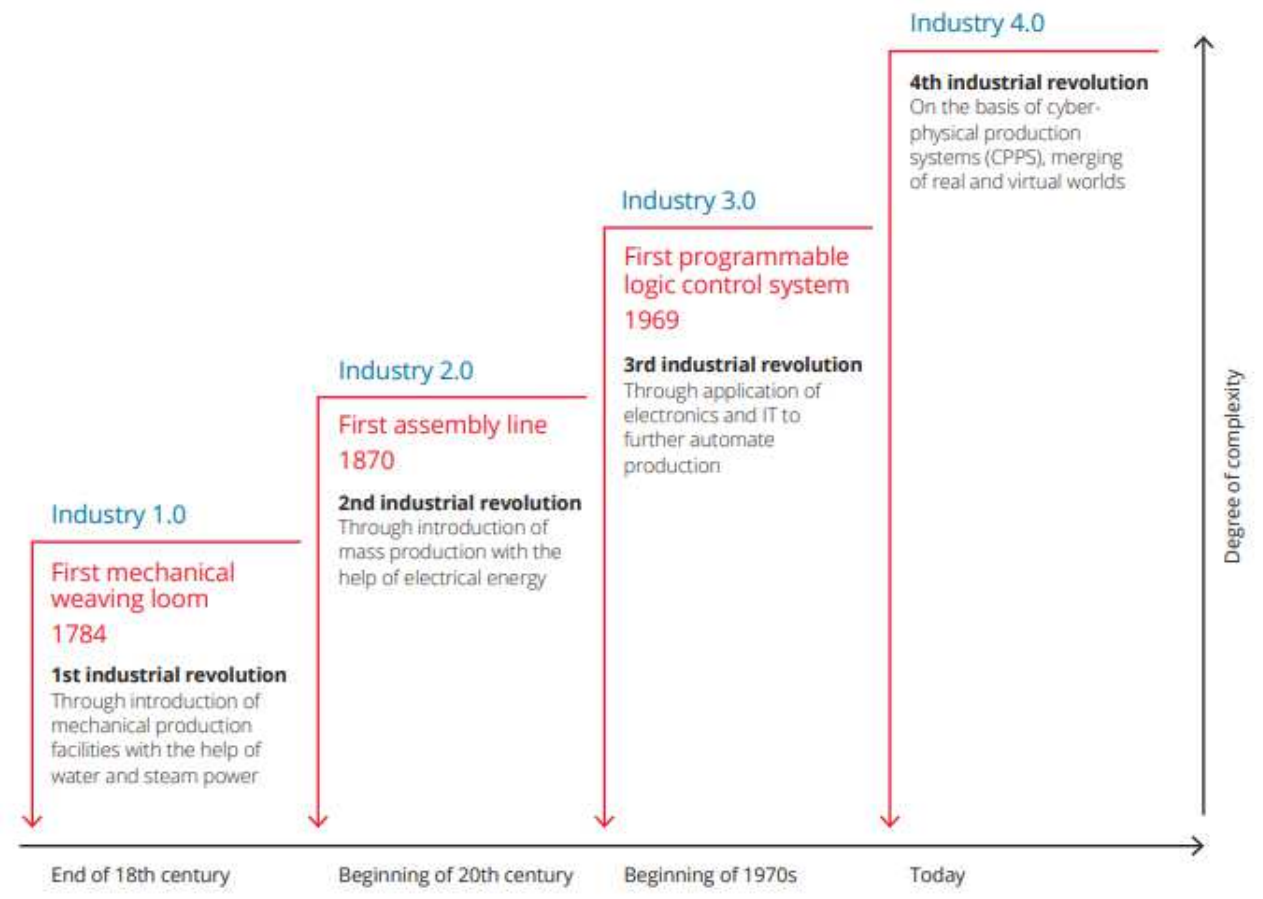

Figure 1. Industrial revolutions in the global economy between eighteenth and twenty-first century Source: Gallagher et al. (2017, p. 6).

Still, the barriers may hinder and slow the revolution's advancement. These barriers include the following (Schwab, 2016, pp. 2-8; PwC, 2014, pp. 36-37; European Commission, 2019, pp. 20-21):

- technical barriers involved in developing and putting the most viable inventions into practice;

- high R\&D costs and those of producing digital devices;

- insufficient resources of adequately skilled workers who could cooperate with one another and operate modern devices;

- traditionalism, conservative attitudes, and apprehension about risk on the part of top management;

- the lack of standards, norms, and possibilities to certify digital devices;

- the lack of adequate data network security and the risk of cyber-attacks and piracy in trading;

- the risk of redundancy in IT/ICT departments of commercial companies;

- uncertainty as to the projected economic effects of technologies to be installed;

- workers' and trade unions' concerns and protests over possible job losses in result of 'machines' replacing the workforce.

The obstacles encountered in trading in modern technologies will also be linked to countries' regulatory frameworks. Pressured by business lobbyists, governments could make decisions restricting foreign competition in multiple ways. Pursuing strategic trade policy - one that fosters 'national' champions may lead to erecting import barriers to goods produced with 4IR technologies and to digitally-intensive products. Moreover, the cross-border flow of sensitive data could be blocked, as these might be taken advantage of by foreign competitors from the digital industry. Furthermore, this type of information may pose a threat to state security, or it may breach privacy and violate access to government information pertaining different areas of the state economy such as finance, healthcare, taxes, or education. These restrictive regulations find their justification in aims pursued by public policy, i.e. protecting privacy against cyber-attacks and safeguarding consumer interests and intellectual property rights. However, 
these measures might sometimes be masking a pursuit of trade protectionism. One could illustrate the regulatory barriers to digital trade with the following examples (Ciurlak \& Ptashkina, 2018, pp. 6-8):

- discriminatory provisions on online sale or a ban on online sale;

- restricting foreign companies in their access to electronic platforms or digital service provision;

- deploying web filtering and blocking;

- restricting online advertisements;

- restricting online payments;

- implementing national standards and requiring registration and testing of 4IR devices;

- the requirement of waiving patent rights, giving up trade secrets, source codes, and technological mandates;

- the inadequate protection of patent rights, copyright, and trade secrets;

- software piracy;

- the requirement of cooperation with local entities (e.g. by establishing a joint venture);

- tariff and non-tariff barriers to ICP products;

- restricting participation of foreign companies in government tenders in such areas as telecommunication and software provision.

What will be of utmost importance for the digital development and removal of regulatory barriers will prove to be international cooperation, the integration of regional groups, and actions taken by such world organizations as the World Trade Organization, the Organization for Economic Cooperation and Development, the International Labour Organization. They already are undertaking measures in this sphere by framing and publishing a variety of guidelines and recommendations. However not binding in nature, these documents merely promote 'good' practices among countries active in digital trade. Still, given that individual countries vary in the extent of their involvement in digital trade - not infrequently with divergent interests - we should not expect a prompt solution to the major issues concerning crossborder digital trade, especially with the future of this trade facing so many uncertainties (OECD, 2017).

\section{CONCLUSIONS}

Trade openness has a positive impact on exports and imports (Loganathan, Karakunnel, \& Victor, 2020). The digital revolution, referred to as the Fourth Industrial Revolution - whose advent is generally believed to have come with the early twenty-first century - will change the nature and forms of manufacturing processes and trade in goods and services. Globalization and regionalism are making them ever more international. This means that goods and services are becoming more complex and more costly in their realization. We may safely assume that the modern technologies and devices will play a critical role in overcoming these barriers to the development of global economy. The vast number of these devices - including computers, the Internet, and mobile phones - was already in use during the Third Industrial Revolution; what we are witnessing now is their further development. Other inventions - including the Internet of Things, cloud computing, big data, artificial intelligence, 3D printing, augmented reality, Blockchain, nanomaterials, and synthetic biology - are at the stage of advanced research, with their experimental use about to be tested in practice. These innovations are expected to significantly impact the growth of world trade volume, also leading to a decline in its costs and information asymmetry, besides shortening the time needed for transaction completion and the delivery of goods and services. The digital era will see the international transfer marked by reliability, punctuality, security, the elimination of losses caused by errors and fraud, along with a high guarantee that payments will be made.

We will also witness substantial changes to the structure of world trade. First and foremost, the growth trend of services will accelerate, including services that in the past could not be delivered from a distance, as they required face-to-face contact such as medical, design, advisory, control, monitoring, and education services. The Internet of Things, online platforms, smart devices, Blockchain, and other instruments within the digital infrastructure will greatly simplify the contact between producers, exporters, importers, and consumers by establishing mostly automated transactions. 
For the commodity structure of trade, the share of those goods will grow, which require high transport and logistics costs, but also time-sensitive, certification-intensive, and contract-intensive goods. Moreover, a growing trend will be evident in the trade of information technology goods, but also of those with an added digital element, which will lead to the blurring of differences between a good and a service.

A number of new technologies - most notably 3D printing - will make goods much more diverse and customizable. Manufacturing 'on site', or close to market outlets, will substantially diminish the importance of intermediate production stages and trade - i.e. offshoring and offshore outsourcing to the benefit of reshoring, which in turn, will downplay the importance of global value chains.

We are already witnessing a decline in the trade share of goods defined as fulfilling the digitalization criteria, recorded on CDs and DVDs in favour of their digital equivalents.

The declining trade costs and diminished relevance of trade's material infrastructure may considerably increase the share of small and medium-sized companies and of developing countries, provided that they develop their digital infrastructure and introduce regulations that will facilitate this commerce.

The above presented trends in the development of international trade are speculative in their nature and draw on the observations and logical analysis concerned with the impact of technical progress on the patterns of manufacturing and international trade in the past and today.

The implementation of the 4IR devices will change trade conditions substantially. First-movers will benefit the most in line with the rule, 'the winner takes it all.' Developed countries will enjoy the best competitive chances given their advantage in terms of capital and technology. However, with falling trading costs and declining requirements for trade's material infrastructure, small and medium-sized enterprises from developing countries will be able to increase their world trade share. However, this will still depend on their capability to implement digital technology (Vlados \& Chatzinikolaou, 2019). In this area, developing countries should be able to receive substantial support from their governments and local authorities, but also international organizations.

The literature has made attempts at using econometric models and computer simulations to evaluate the quantitative impact of the 4IR on the growth and composition of world trade. For example, some project that its volume will grow by two percent by 2030, with the service share seeing an increase from $11 \%$ to $25 \%$ (WTO, 2018, pp. 18-117). However, a different development scenario is also possible. Unpredictable events such as natural disasters, pandemics (e.g. coronavirus), physical and cyber warfare, climate disturbances, and government policies may result in the reversal or a major slowdown of globalization processes, hence of world trade as one of the key components of globalization.

\section{REFERENCES}

Aepli, M., Angst, V., Iten, R., Kaiser, H., Lüthi, I., \& Schweri, J. (2017). Die Entwicklung der Kompetenzanforderung auf dem Arbeitsmarkt im Zuge der Digitalisierung. Arbeitsmarktpolitik, 47, 1-100.

Agrawal, A., Gans, J., \& Goldfarb, A. (Eds.) (2019). The economics of artificial intelligence. Chicago and London: The University of Chicago Press.

Androniceanu, A., Kinnunen, J., \& Georgescu, I. (2020). E-Government clusters in the EU based on the Gaussian Mixture Models. Administratie si Management Public, 35, 6-20. https://doi.org/10.24818/amp/2020.35-01

Androniceanu, A.-M., Georgescu, I., Tvaronavičiene, M., \& Androniceanu, A. (2020). Canonical Correlation Analysis and a New Composite Index on Digitalization and Labor Force in the Context of the Industrial Revolution 4.0. Sustainability, 12(17), Article number: 6812. https://doi.org/10.3390/su12176812

Axxsys. (2018). The fourth industrial revolution: impact on financial services. Axxsys Consulting EMEA.

Bilan, Y., Mishchuk, H., Roshchyk, I., \& Joshi, O. (2020). Hiring and retaining skilled employees in SMEs: problems in human resource practices and links with organizational success. Business: Theory and Practice, 21(2), 695707. https://doi.org/10.3846/btp.2020.12750

Brown, G., \& Whittle, R. (2020). Algorithms, Blockchain \& Cryptocurrency: Implications for the Future of the Workplace. Bringley: Emerland Publishing Limited.

Ciuriak, D., \& Ptashkina, M. (2018). The digital transformation and the transformation of international trade. Geneva: International Centre for Trade and Sustainable Development. 
Dima, A.M., \& Maassen, M.A. (2018). From Waterfall to Agile software: Development models in the IT sector, 2006 to 2018. Impacts on company management. Journal of International Studies, 11(2), 315-326. https://doi.org/10.14254/2071-8330.2018/11-2/2

European Commission. (2018). Capitalising on the benefits of the 4th industrial revolution. Brussels: European Commission Directorate-General for Research and Innovation.

Gallagher, S. (2017). Industry 4.0 Testlabs in Australia Preparing for the Future A report of the Prime Minister's. Industry 4.0 Taskforce - Industry 4.0 Testlabs Workstream.

Ganne, E. (2018). Can blockchain revolutionize international trade? Geneva: World Trade Organization.

Gorączkowska, J. (2020). Enterprise innovation in technology incubators and university business incubators in the context of Polish industry. Oeconomia Copernicana, 11(4), 799-817. https://doi.org/10.24136/oc.2020.032

Gravili, G., Benvenuto, M., Avram, A., \& Viola, C. (2018). The influence of the Digital Divide on Big Data generation within supply chain management. The International Journal of Logistics Management, 29(2), 592-628. https://doi.org/10.1108/IJLM-06-2017-0175

Grochal-Brejdak, M., \& Szymura-Tyc, M. (2018). The Internationalisation Process of an E-Commerce Entrepreneurial Firm: The Inward-Outward Internationalisation and the Development of Knowledge. Entrepreneurial Business and Economics Review, 6(4), 103-123. https://doi.org/10.15678/EBER.2018.060406

Hradecká, M. (2019). Robotic Internal Audit - Control Methods in the Selected Company. AGRIS on-line Papers in Economics and Informatics, 11(2), 31-42. https://doi.org/10.7160/aol.2019.110204

Hu, X., Ocloo, C.E., Akaba, S., \& Worwui-Brown, D. (2019). Effects of business-to-business e-commerce adoption on competitive advantage of small and medium-sized manufacturing enterprises. Economics and Sociology, 12(1), 80- 99. https://doi.org/10.14254/2071-789X.2019/12-1/4

Ismail, N.W. (2020). Digital trade facilitation and bilateral trade in selected Asian countries. Studies in Economics and Finance, ahead-of-print. https://doi.org/10.1108/SEF-10-2019-0406

Kavčáková, M., \& Kočišová, K. (2020). Using Data Envelopment Analysis in Credit Risk Evaluation of ICT Companies. AGRIS on-line Papers in Economics and Informatics, 12(4), 47-60. https://doi.org/10.7160/aol.2020.120404

Kozul-Wright, R. (2016). Robots and Industrialization in developing countries. UNCTAD Policy in Brief No. 50. Geneva: United Nations Conference on Trade and Development.

Krykavskyy, Y., Pokhylchenko, O., \& Hayvanovych, N. (2019). Supply chain development drivers in industry 4.0 in Ukrainian enterprises. Oeconomia Copernicana, 10(2), 273-290. https://doi.org/10.24136/oc.2019.014

Leering, R. (2017). 3D printing: a threat to global trade. Amsterdam: ING Economic and Financial Analysis.

Lechman, E. (2018). Networks Externalities as Social Phenomenon in the Process ICT Diffusion. Economics and Sociology, 11(1), 22-43. https://doi.org/10.14254/2071-789X.2018/11-1/2

Leko Šimić, M., Biloš, A., \& Mijoč, J. (2019). E-business tools adoption and export performance: Empirical evidence from Croatian companies. Journal of Entrepreneurship, Management and Innovation, 15(4), 11-34. https://doi.org/10.7341/20191541

Linz, C., Zimmermann, A., \& Müller-Stewens, G. (2017). Radical business model transformation. London: Kogan Page.

Liu, C. (2017). International Competitiveness and the Fourth Industrial Revolution. Entrepreneurial Business and Economics Review, 5(4), 111-133. https://doi.org/10.15678/EBER.2017.050405

Loganathan, S., Karakunnel, J.J., \& Victor, V. (2020). Analysis of India's trade patterns and trade possibilities with the European Union. Forum Scientiae Oeconomia, 8(4), 5-25. https://doi.org/10.23762/FSO_VOL8_NO4_1

Lopez-Gonzalez, J. (2017). Digital Trade: Developing a Framework for Analysis. OECD Trade Policy Papers No. 205.

Lula, P., Oczkowska, R., Wiśniewska, S., \& Wójcik, K. (2019). An attempt to estimate the competency gap in the IT sector. International Entrepreneurship Review (Przedsiębiorczość Międzynarodowa), 5(3), 95-112. https://doi.org/10.15678/IER.2019.0503.07

Lund, S., \& Manyika, J. (2016). Strengthening the global trade and investment system for sustainable development. Geneva: International Centre for Trade and Sustainable Development.

Maciejewski, M., \& Głodowska, A. (2020). Economic development versus growing importance of the financial sector: Global insight. International Entrepreneurship Review, 6(3), 77-90. https://doi.org/10.15678/IER.2020.0603.06

Majerova, J. (2019). Digital socio-economic platforms in the era of Industry 4.0 (Editorial). Forum Scientiae Oeconomia, 7(4), 5-6. 
Manyika, J., Lund, S., Bughin, J., Woetzel, J., Stamenov, K., \& Dhingra, D. (2016). Digital globalization. The new era of global flows. Pennsylvania: McKinsey Global Institute.

Melzer, J.P. (2016). Maximizing the opportunities of the internet for international trade. Geneva World Economic Forum - International Centre for Trade and Sustainable Development.

Młody, M. (2018). New production patterns and the future of manufacturing relocation trend in the 4.0 era: The perspective of consumers. International Entrepreneurship Review (Przedsiębiorczość Międzynarodowa), 4(3), 287-302.

Nwabueze, U., \& Mileski, J. (2018). Achieving competitive advantage through effective communication in a global environment. Journal of International Studies, 11(1), 50-66. https://doi.org/10.14254/2071-8330.2018/11-1/4

Nowiński, W., \& Kozma, M. (2017). How Can Blockchain Technology Disrupt the Existing Business Models?. Entrepreneurial Business and Economics Review, 5(3), 173-188. https://doi.org/10.15678/EBER.2017.050309

Nwoke, U. (2020). Imposition of trade tariffs by the USA on China: implications for the WTO and international trade law. Journal of International Trade Law and Policy, 19(2), 69-84. https://doi.org/10.1108/JITLP-012019-0003

OECD. (2017). The future of global value chains. Science, Technology and Innovation Policy Papers, No 41. Paris: Organization for Economic Cooperation and Development.

Paliokaite, A. (2019). An innovation policy framework for upgrading firm absorptive capacities in the context of catching-up economies. Journal of Entrepreneurship, Management and Innovation, 15(3), 103-130. https://doi.org/10.7341/20191534

Park, S.C. (2017). RCEP versus TPP with the Trump Administration in the USA and Implications for East Asian Economic Cooperation. Entrepreneurial Business and Economics Review, 5(4), 135-152. https://doi.org/10.15678/EBER.2017.050406

Pini, M. (2019). Family management and Industry 4.0: Different effects in different geographical areas? An analysis of the less developed regions in Italy. Journal of Entrepreneurship, Management and Innovation, 15(3), 73-102. https://doi.org/10.7341/20191533

Pisar, P., \& Bilkova, D. (2019). Controlling as a tool for SME management with an emphasis on innovations in the context of Industry 4.0. Equilibrium. Quarterly Journal of Economics and Economic Policy, 14(4), 763-785. https://doi.org/10.24136/eq.2019.035

PwC. (2014). Industrie 4.0: Chancen und Herausforderungen der vierten industriellen Revolution. Berlin: PwC Strategy \& $\mathrm{GmbH}$.

Pohlová, K., Smutka, L., Laputková, A., \& Svatoš, M. (2018). Czech Agrarian Foreign Trade According to the Degree of Processing. AGRIS on-line Papers in Economics and Informatics, 10(3), 103-118. https://doi.org/10.7160/aol.2018.100309

Ratten, V. (2020). Coronavirus (Covid-19) and the entrepreneurship education community. Journal of Enterprising Communities: People and Places in the Global Economy, ahead-of-print. https://doi.org/10.1108/JEC-062020-0121

Rymarczyk, J. (2012). Biznes międzynarodowy. Warszawa: PWE.

Rymarczyk, J. (2020). Technologies, Opportunities and Challenges of the Industrial Revolution 4.0: Theoretical Considerations. Entrepreneurial Business and Economics Review, 8(1), 185-198. https://doi.org/10.15678/EBER.2020.080110

Schwab, K. (2016). The fourth industrial revolution: what it means, how to respond. Geneva: World Economic Forum.

Sieja, M., \& Wach, K. (2019). The Use of Evolutionary Algorithms for Optimization in the Modern Entrepreneurial Economy: Interdisciplinary Perspective. Entrepreneurial Business and Economics Review, 7(4), 117-130. https://doi.org/10.15678/EBER.2019.070407

Strange, R., \& Zucchella, A. (2017). Industry 4.0: global value chains and international business. Multinational Business Review, 25(3), 174-184. https://doi.org/10.1108/MBR-05-2017-0028

Ślusarczyk, B. (2018). Industry 4.0 - Are we ready?. Polish Journal of Management Studies, 17(1), 232-248. https://doi.org//10.17512/pjms.2018.17.1.19

Świadek, A., Dzikowski, P., Tomaszewski, M., \& Gorączkowska, J. (2019). Sectoral patterns of innovation cooperation in Polish industry. Equilibrium. Quarterly Journal of Economics and Economic Policy, 14(1), $183-200$. https://doi.org/10.24136/eq.2019.009 
Świadek, A., \& Gorączkowska, J. (2020). The institutional support for an innovation cooperation in industry: the case of Poland. Equilibrium. Quarterly Journal of Economics and Economic Policy, 15(4), 811-831. https://doi.org/10.24136/eq.2020.035

Tan, S.W. (2017). Digital trade Europe and Central Asia. ADBI Working Paper Series, 751, 1-29.

Upadhyay, N. (2019). UnBlock the Blockchain. Singapore: Springer.

Vlados, C., \& Chatzinikolaou, D. (2019). Business ecosystems policy in Stra.Tech.Man terms: The case of the Eastern Macedonia and Thrace region. Journal of Entrepreneurship, Management and Innovation, 15(3), 163197. https://doi.org/10.7341/20191536

Weber, J., \& Gneuss, M. (2017). Digital Geschäftsmodelinnovationen. Controlling in der digitalen Transformation, Internationaler Controller Verein. Retrieved from https://www.icv-controling.com on November 20, 2019.

Woodward, M. (2017). The need for speed: regulatory approaches to high frequency trading in the United States and the European Union. Vanderbilt Journal of International Law, 50(5).

Wyciślak, S. (2017). Implications of digitalization for value chains. International Entrepreneurship Review (Przedsiębiorczość Międzynarodowa), 3(2), 37-48. https://doi.org/10.15678/PM.2017.0302.03

WTO. (2018). World Trade Report 2018. The future of world trade: how digital technologies are transforming global commerce. Geneva: World Trade Organization.

\section{Author}

\section{Jan Rymarczyk}

Full professor, currently working at the WSB University in Poznań (Poland). His research interests include international business and international trade.

Correspondence to: Prof. dr hab. Jan Rymarczyk, Wyższa Szkoła Bankowa w Poznaniu, Powstańców Wielkopolskich 5, 61-874 Poznań, Poland, e-mail: jan.rymarczyk@wsb.poznan.pl ORCID (1) http://orcid.org/0000-003-4701-439X

\section{Acknowledgements and Financial Disclosure}

I would like to thank anonymous reviewers for constructive feedback and comments.

\section{Conflict of Interest}

The author declares that the research was conducted in the absence of any commercial or financial relationships that could be construed as a potential conflict of interest.

\section{Copyright and License}

This article is published under the terms of the Creative Commons

Attribution - NoDerivs (CC BY-ND 4.0) License

http://creativecommons.org/licenses/by-nd/4.0/ 
